\title{
LETRAS E SILÊNCIOS: A LITERATURA DE AUTORIA FEMININA NA PARAÍBA
}

\section{LETTERS AND SILENCES: THE FEMALE AUTHORIAL LITERATURE IN PARAÍBA}

\section{Marcelo Medeiros da Silva* \\ $U E P B$}

Resumo: O artigo reflete sobre a literatura de autoria feminina na Paraíba e aponta os nomes de mulheres que procuram, nesse lugar de afeto, fazer da literatura um espaço para si, um local de visibilidade para falar de identidade de gênero e de outras mulheres, igualmente presas ao sistema de sexo/gênero. Para tanto, seguiremos as orientações de Barbosa Filho (2003, 2011), Campos Júnior (2015), Muzart (2006), Perrot (2005) Schmidt (1995). Assim, esperamos contribuir com os estudos que procuram compreender como, a partir de um discurso próprio, as mulheres se incorporaram à cultura de seu país e de seu estado, no que diz respeito a seus mitos e crenças, imaginário e ideologia, formas de ser e de existir.

Palavras-chave: Vozes marginais. Cânone Literário. Autoria Feminina. Literatura Paraibana

\begin{abstract}
The paper reflects on the female authorial literature in Paraíba and points out the names of women looking, a place of affection, make literature a space for itself a place of visibility to talk about of gender identity and others women, also attached to the system sex/gender. To do so, we will follow the guidelines of Barbosa Filho (2003, 2011), Campos Júnior (2015), Muzart (2006), Perrot (2005) Schmidt (1995). Thus, we hope to contribute to the studies search for to understand how, from a discourse itself, we have joined the culture of their country and their region. Regarding their myths and beliefs, imaginary and ideology, means of being and to existing.
\end{abstract}

Key words: Marginal voices. Literary Canon. Female Authorial. Paraiba’s Literature.

\section{Introdução}

Entre nós e as palavras há metal fundente entre nós e as palavras há hélices que andam e podem dar-nos a morte violar-nos tirar do mais fundo de nós o mais útil segredo entre nós e as palavras há perfis ardentes espaços cheios de gente de costas

\author{
* Doutor em Letras \\ pela Universidade \\ Federal da Paraíba \\ e docente da \\ Universidade \\ Estadual da Paraíba, \\ onde é membro \\ permanente do \\ Programa de \\ Pós-Graduação \\ em Formação de \\ Professores, professor \\ de Literatura \\ do campus VI e \\ coordenador da área \\ de Língua Portuguesa \\ do PIBID.
}


altas flores venenosas portas por abrir e escadas e ponteiros e crianças sentadas à espera do seu tempo e do seu precipício $[\ldots]$

Entre nós e as palavras, os emparedados e entre nós e as palavras, o nosso dever falar.

(Mário Cesariny)

Quando voltamos o nosso olhar para a história oficial de nossa literatura, deparamo-nos com um grande vazio: a inexistência de escritos produzidos por grupos minoritários (mulheres, negros, gays, pobres). O desconhecimento de tal produção tem uma explicação cultural. Em se tratando da produção de autoria feminina, em nosso país, como lembra Schmidt (1995), a tradição estética é de base europeia e disseminou, em nosso imaginário, a ideia de que os homens haviam nascido para criarem enquanto às mulheres tinha sido concedido apenas o dom da procriação. Logo, a criação artística só poderia ser uma atividade masculina: "tal qual Deus Pai que criou o mundo e o nomeou pelo poder do Verbo, o artista sempre foi visto em um papel análogo ao papel divino sendo, portanto, considerado o progenitor de seu texto, um patriarca estético" (SCHMIDT, 1995, p. 184). Se a escrita era um ato divino, ela, dentro da lógica patriarcal, só poderia ser domínio do masculino. Por isso, escrever foi uma atividade, durante muito tempo, negada ao sexo feminino. As mulheres que se atreveram a infringir essa determinação social foram vistas negativamente, o que fez com que muitas delas, que se sentiam compelidas ao exercício da escrita, se valessem de pseudônimos masculinos ou do próprio anonimato não só como meio de resguardarem-se das possíveis retaliações que poderiam sofrer, mas também como forma de resistência e inserção no universo literário.

A trajetória percorrida pelas mulheres no universo das belas letras foi, portanto, marcada por lutas, enfretamentos, avanços e recuos para poderem se firmar como escritoras em um cenário eminentemente masculino. Com o advento da crítica literária de cunho feminista, vamos começar a colocar em xeque a misoginia do nosso cânone literário e empreender uma busca incessante por obras produzidas por mulheres, evidenciando que as escritoras de outrora sofreram, em seu trabalho nas Letras, do mal da época que incluía a falta de instrução, de direitos legais, o não reconhecimento das mulheres como cidadãs, problemas esses, em parte, solucionados contemporaneamente, mas aos quais se somaram outros que envolvem publicação, circulação, comercialização.

Ante esse cenário de luta, resistência e exclusão, vêm-nos as seguintes inquietações: na Paraíba, a situação da mulher-escritora foi análoga à forma descrita anteriormente? Que mulheres na Paraíba fizeram da escrita literária um exercício também para o feminino? No caso do primeiro 
questionamento, uma resposta rápida seria dizer que não só na Paraíba como em todo o nosso país, em todo o Ocidente, a inserção das mulheres no hermético mundo das Letras não foi uma empreitada fácil. Afinal, escrever era considerado algo que, dentro da ideologia do patriarcado, quebrava a concepção de feminilidade, de fragilidade própria do feminino. Escrever era, portanto, uma atividade que exigia atividade mental, conexões com o mundo da ação, aspectos estes que estavam distantes da concepção que se tinha a respeito da condição feminina e dos atributos inerentes ao “sexo frágil”. Ainda assim, as mulheres escreveram. Todavia, a política de silenciamento que tornou invisível "a legitimidade cultural da mulher como sujeito do discurso exercendo funções de significação e representação” (SCHMIDT, 1995, p. 183) perdurou, em nossa literatura, até meados da década de 1970, período em que apenas três escritoras eram conhecidas do grande público e da crítica: Raquel de Queiroz (1910-2003), Cecília Meireles (1901-1964) e Clarice Lispector (1920-1977).

Para responder ao segundo questionamento, lembremos que escrever sobre a vida e a obra de escritoras desconhecidas, isto é, que não fazem parte dos ilustres imortais de nossa literatura, é um trabalho árduo que exige paciência para poder chegar às fontes, muitas vezes, bastante esparsas e esgarçadas pelo tempo, já que, como se não bastasse a ausência da mulher nos grandes relatos, o estudioso ou a estudiosa se deparam, geralmente, com a carência de traços sobre as mulheres nas fontes que lhes servem como estudo (PERROT, 2005). Por isso, na esteira dos trabalhos desenvolvidos por Muzart (2000, 2004 e 2009), Duarte (2008) e Mendes et al. (2009), o presente artigo visa refletir sobre a literatura de autoria feminina na Paraíba, visto que até agora poucos são os trabalhos que têm procurado investigar a contribuição das mulheres às letras paraibanas. Nosso intuito, a partir de uma perspectiva historiográfica, é ir apontando os nomes das mulheres que procuram, em solo paraibano, fazer da literatura um espaço para si, um local para falar de si, de outras mulheres e dos eventos em seu entorno. Interessanos, sobretudo, chegar aos nomes de nossas predecessoras, posição social que as mulheres-escritoras de tempos idos tentaram ocupar, apesar do temor “de que por não pode(rem) criar, de que, por não poder(em) tornar-se ela(s) própria(s) predecessora(s), o ato de escrever a(s) isolasse ou a(s) destruísse (...)” (CAMPOS, 1992, p. 120).

Assim, na busca por nossas predecessoras paraibanas, ensejamos investigar não só quais as mulheres fazem parte do cenário literário paraibano, mas também o que o discurso historiográfico local afirma acerca da produção literária de mulheres e qual o local dedicado à produção de autoria feminina em historiografias literárias paraibanas. Para tanto, valemo-nos, primeiramente, de historiografias literárias, depois, de dicionários de mulheres, coletâneas e antologias literárias e, por fim, da internet como fontes de consulta, conforme ilustra a tabela abaixo: 


\begin{tabular}{|l|}
\hline \multicolumn{1}{|c|}{ CORPUS DE INVESTIGAÇÃO } \\
\hline $\begin{array}{l}\text { Dicionário Bibliográfico do Autor da Microrregião do } \\
\text { Agreste da Borborema, publicado em } 1982 \text { e de autoria da } \\
\text { Professora Elizabeth Marinheiro. }\end{array}$ \\
\hline $\begin{array}{l}\text { Dicionário Crítico de Escritoras Brasileiras publicado no } \\
\text { ano de } 2002 \text { em São Paulo pela professora Nelly Novaes } \\
\text { Coelho }\end{array}$ \\
\hline $\begin{array}{l}\text { Dicionário de Mulheres, de autoria de Hilda Agnes Hübner } \\
\text { Flores, publicado em 1999. }\end{array}$ \\
\hline $\begin{array}{l}\text { Dicionário Mulheres do Brasil, de Schuma Schumaher e } \\
\text { Érico Vital Brazil, publicado no ano de 2000. }\end{array}$ \\
\hline $\begin{array}{l}\text { Antologia de Escritoras Brasileiras do Século XIX que } \\
\text { foram organizadas em três volumes pela professora Zahidé } \\
\text { Lupinacci Muzart e publicada pela Editora Mulheres. }\end{array}$ \\
\hline $\begin{array}{l}\text { Ensaístas Brasileiras, das autoras Heloisa Buarque de } \\
\text { Hollanda e Lucia Nascimento Araújo, publicado no ano de } \\
\text { 1993. }\end{array}$ \\
\hline $\begin{array}{l}\text { Antologia Contemporânea da Poesia Paraibana, organizada } \\
\text { por Heriberto Coelho, publicada em 1995. }\end{array}$ \\
\hline $\begin{array}{l}\text { Dicionário Literário da Paraíba, organizado por Idelette } \\
\text { Muzart Fonseca dos Santos. }\end{array}$ \\
\hline $\begin{array}{l}\text { Coletânea Autores Paraibanos - Poesia, de Ângela Bezerra } \\
\text { de Castro, publicado no ano de 2005. }\end{array}$ \\
\hline $\begin{array}{l}\text { Coletânea de Autores Paraibanos - Prosa, de Ângela } \\
\text { Bezerra de Castro, publicada no ano de 2005. }\end{array}$ \\
\hline $\begin{array}{l}\text { Antologia 25 Mulheres que estão fazendo a nova Literatura } \\
\text { Brasileira e Mais 30 mulheres que estão fazendo a nova } \\
\text { Literatura Brasileira, ambas organizadas por Luiz Ruffato, } \\
\text { publicada no ano de 2005. }\end{array}$ \\
\hline
\end{tabular}

O recurso a tal corpus objetivou reunir o maior número de menção a escritoras paraibanas. Por escritoras paraibanas, entendemos, inicialmente, o conjunto de obras que foram produzidas por mulheres nascidas na Paraíba, a exemplo de Clotilde Tavares, que, embora tendo ido morar em Natal, não perdeu de todo a relação com seu estado de origem. Entretanto, como o lugar de origem não é suficiente para definir um/a escritor/a como pertencente à determinada região, estado ou local, alargamos o conceito de escritora paraibana para contemplar também o conjunto de obras escritas por mulheres que se radicaram paraibanas, como é o caso de Maria do Socorro Xavier, ou o conjunto de obras cujas autoras, fazendo da Paraíba seu lugar de afeto, porque nele estabeleceram morada, constituíram família e laços de amizade e/ou profissionais, ainda que não tenham se radicado oficialmente, tiveram em nosso Estado as condições necessárias para a produção, circulação e recepção de maneira que autoras e obras estejam incorporadas ao cânone literário de nosso Estado, como é o caso da poetisa Vitória Lima e da teatróloga Lourdes Ramalho. A análise do referido corpus nos levou a um número expressivo de escritoras que nos legaram uma produção literária que 
engloba romances, poesias, teatro, crônicas, livro de memórias dentre outros gêneros, o que revela que a mulher-escritora-paraibana não foi produtora de um gênero só e não aceitou como valores femininos a subordinação social, o guardar as palavras no fundo de si mesmas, o conformar-se, o obedecer, o submeter-se e o calar-se (PERROT, 2005).

\section{Vozes femininas na literatura paraibana: esboços para uma cartografia}

Como se pode depreender pelo que expusemos na introdução, a exclusão de textos de autoria feminina, assim como de sujeitos que não fazem parte de grupos hegemônicos, tais como índios, negros, gays, lésbicas, é uma mostra de que a natureza intrínseca da historiografia literária parece ser o inevitável par seleção/exclusão que rege a escolha ou não dos fatos literários, das obras e dos/as autores/as. O problema da presença desse par como ferramenta operacional no processo de escritura de uma historiografia literária está, a nosso ver, na forma como tal processo é conduzido, visto que os sujeitos - em sua maioria pertencentes à matriz heterossexual - que determinam o que deve ser selecionado e o que deve ser excluído agem de maneira consciente, parcial e, por isso mesmo, suscetível de revisão.

No que diz respeito à literatura produzida em solo paraibano, notamos, em nosso exercício docente, um completo desconhecimento dos nomes expressivos em nossas Letras, sejam obras de autoria feminina, sejam obras de autoria masculina, exceto o de alguns que conseguiram projeção nacional e que, todavia, são todos do sexo masculino, como se apenas homens produzissem literatura no referido estado. Uma razão para esse silêncio acerca da produção local pode ser depreendida das seguintes palavras de Gilberto Mendonça Telles (2000 apud BARBOSA FILHO, 2003, p. 41):

[...] A maioria dos críticos e dos historiadores de literatura não pesquisa, acha melhor repetir o repetido. É só comparar uma história literária com outra. As universidades, por sua vez, têm medo de trabalhar com o novo, e investem continuamente nos autores que estão na mídia. Dá uma tristeza saber que uma universidade, de que região for, não consegue ver o escritor da sua região, vendo apenas Guimarães Rosa, Clarice Lispector, quase sempre os escritores que foram estudados nas dissertações e teses que, diga-se de passagem, pouco trazem de novidade para a comunidade científica do país, a não ser os diplomas e promoções... pessoais.

Sem querer dizer com a fala acima que devemos deixar de lado os grandes nomes da literatura de nosso país em favor de escritores/as locais, é preciso ter consciência de que falta visibilidade para a produção local e que ela é digna de ser objeto de estudo. Acerca dessa necessidade imperiosa de tornar visível os nossos valores literários, afirma o crítico paraibano Hildeberto Barbosa Filho: 
[...] é chegada a hora da universidade paraibana, sobretudo através de seus cursos de Letras, atentar para o fato de que existe uma produção literária local, toda uma fortuna crítica mais ou menos disponível e um repertório elasticamente variado de assuntos, obras, autores, tendências, grupos, publicações e outras modalidades temáticas que poderão suprir muito bem o interesse científico e cognitivo de alunos, professores, historiadores, críticos e estudiosos em geral. Tal atitude poderia germinar, portanto, em dissertações, teses, e obras a serem publicadas (BARBOSA FILHO, 2003, p. 41).

Embora ainda não existam estudos mais sistematizados acerca da produção literária paraibana, exceção feita à produção de críticos como José Mário da Silva ou Hildeberto Barbosa Filho ou de alguns trabalhos acadêmicos (cf. CAMPOS JÚNIOR, 2015), “de certa maneira, a literatura na Paraíba tem estado presente nas salas de aulas, principalmente no âmbito da análise textual, como também tem gerado uma que outra dissertação de mestrado e até teses de doutorado” (BARBOSA FILHO, 2003, p. 42). Isso acontece, porém, "não por injunção de normas curriculares, mas devido o interesse desse ou daquele professor que, sob a liberdade criadora do seu pensamento pedagógico e da sua inquieta atitude de pesquisador, tende a ultrapassar os limites convencionais dos conteúdos programáticos” (BARBOSA FILHO, 2003, p. 42). Logo, a produção literária paraibana é ainda um campo que merece ser devidamente explorado a fim de que possamos trazer à estampa obras e autores/as esquecidos/as e, consequentemente, fazer com que os textos e seus produtores/as sejam lidos, analisados, comparados a fim de fazê-los "emergir do limbo em que se encontram, inserindo-se, portanto, no palco do debate vivo das ideias, ao mesmo tempo em que devemos ajustá-los, em sua significação, aos limites do processo histórico” (BARBOSA FILHO, 2011, p. 15).

Em se tratando de textos produzidos por sujeitos não hegemônicos, como é o caso da literatura de autoria feminina, o objetivo principal dessa releitura é, sobretudo, trazer à tona “o estratégico movimento ideológico perpetuado pela consagração de um texto” e responsável pela censura e silenciamento de textos que sejam, ideologicamente, diferentes. Homogeneizando a diferença, reitera-se, então, um único discurso que, oficialmente permitido, é aceito e consagrado nas escolas, na mídia ao mesmo tempo em que muitas falas são suprimidas, massacradas, reprimidas, naturalizando, por exemplo, a invisibilização da produção literária de autoria feminina. O status quo em nosso campo literário oficial move-se, portanto, graças à roda dos enjeitados, dos marginalizados, dos periféricos. Por causa disso, as nossas historiografias literárias fomentam "um discurso que, sacralizando a história passada, acaba legitimando as estruturas vigentes de poder e seus detentores, especialmente à medida que o cânone e a exegese canonizante só incorporam temas relativos a problemas já solucionados” (KOTHE, 1997, p. 29). 
Assim, no âmbito da literatura paraibana, existem menções à produção literária feminina? O que o discurso historiográfico diz acerca da produção literária de mulheres paraibanas? Quais autoras estão canonizadas na historiografia literária da Paraíba? Para respondermos a essas questões, conforme assinalamos na introdução, valemo-nos, primeiramente, de historiografias literárias, depois, de dicionários de mulheres, coletâneas e antologias literárias. Em seguida, da internet como outra fonte de consulta e, por fim, realizamos visitas a sebos locais para a aquisição de obras críticas bem como literárias, com o fito de identificarmos obras a cujas autoras, possivelmente, não se fazia menção nos dicionários e nos livros de historiografia de que dispúnhamos. Após a realização desses procedimentos, chegamos à lista abaixo que, apesar de não dar conta de todas as escritoras paraibanas, traz um número expressivo de mulheres que fizeram, algumas continuam ainda fazendo, da literatura na Paraíba um ofício também feminino:

QUADRO DE ESCRITORAS PARAIBANAS

\begin{tabular}{|ll|}
\hline 1. & ALINE LISIEUX (FRAZÃO DUTRA) \\
\hline 2. & ADYLLA ROCHA RABELLO \\
\hline 3. & ÁGIDA MARIA ARRUDA COSTA \\
\hline 4. & ALBA MACIEIRA FERREIRA PIRES \\
\hline 5. & ALDINA DE ALMEIDA \\
\hline 6. & ALMIRA ARAÚJO CRUZ SOARES \\
\hline 7. & AMBROSINA MAGALHÃES \\
\hline 8. & AMÉLIA THEORGA AYRES \\
\hline 9. & AMNERES \\
\hline 10. & ANA SALES \\
\hline 11. & ANALICE CALDAS \\
\hline 12. & ANDRÉA D'AMORIM PEREIRA BARROS \\
\hline 13. & ANDRÉIA D’AMORIM PEREIRA \\
\hline 14. & ANDRÉIA FERNANDES MARTINS NUNES \\
\hline 15. & ANDRÉA PEREIRA BARROS \\
\hline 16. & ANGELA (MARIA) BEZERRA DE CASTRO \\
\hline 17. & ANGELA UCHOA CAVALCANTI \\
\hline 18. & ANILDA LEÃO CAVALCANTI LINS \\
\hline 19. & ANNA AMÉLIA APOLINÁRIO \\
\hline 20. & ANTÔNIA LENIRA DE SOUZA GUERRA \\
\hline 21. & APARECIDA DE SANTANA \\
\hline 22. & AURI MESQUITA DE ANDRADE \\
\hline 23. & BARBARA SAID \\
\hline 24. & BELLA SANTIAGO \\
\hline 25. & BELMINDA STELA DE FARIA VINAGRE \\
\hline
\end{tabular}

\begin{tabular}{|ll|}
\hline 26. & BENILDE MOURA \\
\hline 27. & BERNADETE BESERRA \\
\hline 28. & CARMEM COELHO \\
\hline 29. & CÉLIA CARVALHO \\
\hline 30. & CHICA DA ROCINHA \\
\hline 31. & CLÉLIA LOPES DE MENDONÇA \\
\hline 32. & CLÉLIA SILVEIRA \\
\hline 33. & CELESTE CASTOR DE ANDRADE \\
\hline 34. & CLAÚDIA JUSTA GONDIM \\
\hline 35. & CLARRISSA YEMISI \\
\hline 36. & CLOTILDE SANTA CRUZ TAVAREZ \\
\hline 37. & CRISTINA DANTAS \\
\hline 38. & CYELLE CARMEM \\
\hline 39. & DALVANIRA LOPES \\
\hline 40. & DÉA BORBA CRUZ \\
\hline 41. & DEBORAH ROSE GALVÃO DANTAS \\
\hline 42. & DENISE LINO \\
\hline 43. & DILMA STAEL ALEXANDRE MARIZ \\
\hline 44. & DINAH COLARES \\
\hline 45. & DIONE BARRETO \\
\hline 46. & DIRACI DE ARAÚJO VIEIRA \\
\hline 47. & DORA LIMEIRA \\
\hline 48. & DORA MARIA BATISTA \\
\hline 49. & ELEUZINE CARVALHO \\
\hline D0. & ELIANE MAYER RAMALHO \\
\hline
\end{tabular}


continuação

\begin{tabular}{|c|c|}
\hline & ELIANE SIMÕES NILO \\
\hline & $\begin{array}{l}\text { ELIZABETH (FIGUEIREDO AGRA) } \\
\text { MARINHEIRO }\end{array}$ \\
\hline & ELIZETE CASSIANO \\
\hline & EUDÉSIA VIEIRA \\
\hline & EUNICE BOREAL \\
\hline & EZILDA MILANEZ BARRETO \\
\hline & EUGÊNIA MENEZES \\
\hline & FÁTIMA ARAÚJO \\
\hline & FÁTIMA BARROS \\
\hline & FATIMA DE ALMEIDA \\
\hline & FÁTIMA CORDEIRO \\
\hline & $\begin{array}{l}\text { FIDÉLIA CASSANDRA PEREIRA DE } \\
\text { ARAÚJO }\end{array}$ \\
\hline & FRANCISCA EMÍLIA DA FONSECA \\
\hline & GERMANA VIDAL \\
\hline & GISELDA DOS SANTOS MOURA \\
\hline & GLORIA JANE LESSA FEITOSA \\
\hline & GLORINHA GADELHA \\
\hline & GRAÇA BANDEIRA \\
\hline & GRACINHA TELLES \\
\hline & GRAZIELA EMERENCIANO \\
\hline & GUIOMAR CHIANCA \\
\hline & HELENA CAVALCANTI CIRAULO \\
\hline & HELENA PESSOA \\
\hline & HELENA RAPOSO CARNEIRO DA CUNHA \\
\hline & HELOISA BEZERRA \\
\hline & HÉLVIA CALLOU \\
\hline & ICLÉA VASCONCELOS DE FRANCA \\
\hline & ILMA SANTORO \\
\hline & ILZE FONSECA ALEXANDRE \\
\hline & INEZ MARIZ \\
\hline & INOVETE BORGES VIRGOLINO \\
\hline & IONE GOMES BARRETO \\
\hline & IRACEMA MARINHO \\
\hline & IRENE DIAS CAVALCANTI \\
\hline & IRENE SAMPAIO \\
\hline & IRENE SILVA DE MEDEIROS \\
\hline & ISA FERREIRA DOS SANTOS \\
\hline
\end{tabular}

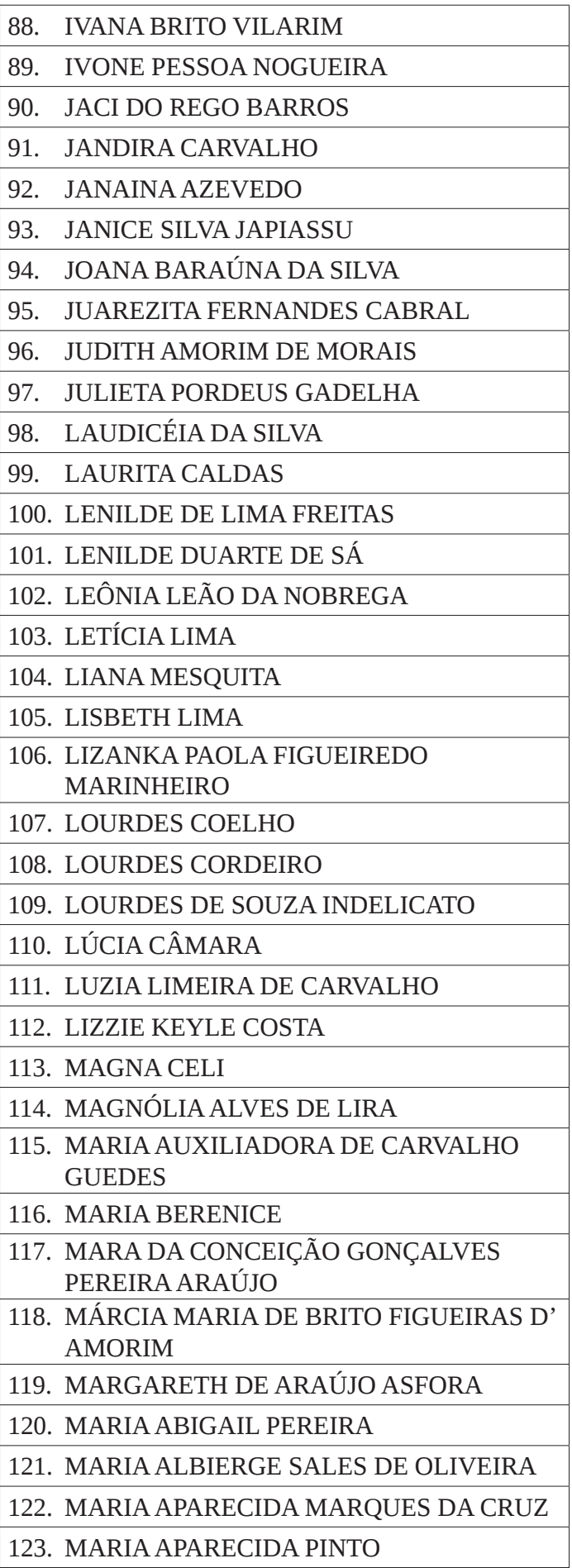


continuação

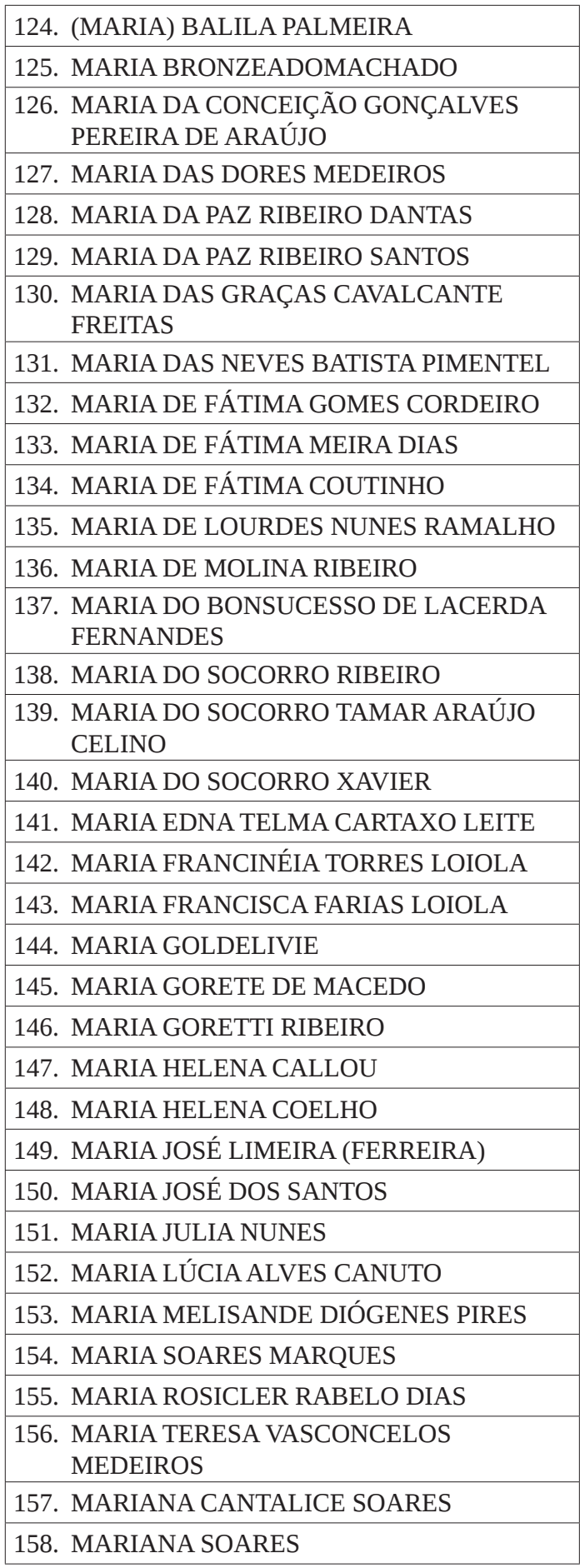

159. MARÍLIA ARNAUD

160. MARILITA POZZOLI

161. MARINALVA FREIRE DA SILVA

162. MARISA ALVARENGA CABRAL

163. MARISA ALVERGA

164. MARISA BARROS

165. MARISINHA BEZERRA DE MEDEIROS

166. MARISTELA BARBOSA DE MENDONÇA

167. MARIZETE SANTOS

168. MARTHA MÔNICA FREIRE DA SILVA

169. MARIA MERCEDES RIBEIRO CAVALCANTI

170. MERCÊS SANTOS FURTADO

171. MICHELLINE BRASIL

172. MILFA ARAÚJO VALÉRIO

173. MIRIAN ASFORA

174. MIRIAM CARLOS FREIRE

175. MIRIAM TOURINHO DINIZ

176. MIRTES WALESKASULPINO

177. MYRIAM GURGEL MAIA

178. NAIR GUSMÃO

179. NEVINHA ARAÚJO

179. NIEDJA AGRA DE ARAÚJO

180. NOEMI PORDEUS GADELHA

181. NÍSIA NÓBREGA

182. NÍSIA LEAL

183. ODETE COSTA SOUZA

184. ODILIA ASSIS ALBUQUERQUE

185. OLIVINA CARNEIRO DA CUNHA

186. ONELLIASETUBAL ROCHA DE QUEIROGA

187. OTACIANA CÁSSIA MOREIRA DA SILVA

188. PALMEIRA GUIMARÃES

189. REGYNA CELLY MEDEIROS

190. REGINA LIRA

191. REJANE SOBREIRA (MINATO)

192. ROCHELLE MELO PEREIRA

193. ROSILDA CARTAXO

194. RITA DE CÁSSIA ALVES 
conclusão

\begin{tabular}{|c|}
\hline 195. SALETE CORDEIRO \\
\hline 196. SAMELLY XAVIER \\
\hline 197. SELMA DE CARVALHO OLIVEIRA \\
\hline 198. SELMA VASCONCELOS \\
\hline 199. SELMA VILAR \\
\hline 200. SHIRLEY STELLA GOMES \\
\hline 201. SÍLVIA PERAZZO BARBOSA \\
\hline 202. SOCORRO LEADEBAL \\
\hline 203. SOCORRO LIRA \\
\hline 204. SÔNIA MARIA SOBREIRA DA SILVA \\
\hline 205. TÂNIA ROCHA \\
\hline 206. TELMA EULÁLIO ALBUQUERQUE \\
\hline $\begin{array}{l}\text { 207. TEKA'S } \\
\text { 208. THEREZA RODRIGUES }\end{array}$ \\
\hline $\begin{array}{l}\text { 209. TERMUTIS DO SOCORRO FIGUEIREDO } \\
\text { AGRA }\end{array}$ \\
\hline 210. TEREZINHA FIGUEIREDO \\
\hline 211. TEREZINHA MONTEIRO LINS FIALHO \\
\hline 212. TETÉ ASSIS DE OLIVEIRA \\
\hline
\end{tabular}

\begin{tabular}{|l|}
\hline 213. VALDÉLIA BARROS \\
\hline $\begin{array}{l}\text { 214. VALÉRIA VILLARIM PIMENTEL NOBRE } \\
\text { ALENCAR }\end{array}$ \\
\hline 215. VALÉRIA VILLARIN ALENCAR \\
\hline 216. VERA FERREIRA \\
\hline 217. VERA LÚCIA BARBOSA \\
\hline 218. VERANEIDE WANDERLEY \\
\hline 219. VERÔNICA LIMA DE ALMEIDA \\
\hline 220. VESPERTINA MELO RIBEIRO \\
\hline 221. VICENTINA VITAL DO RÊGO \\
\hline 222. VILMA MARIA DE MACEDO \\
\hline 223. VIOLETA FORMIGA \\
\hline 224. VITÓRIA LIMA \\
\hline 225. WALDICE MENDONÇA DA SILVA PORTO \\
\hline 226. WILMA WANDA (DE SOUZA EMERI) \\
\hline 227. YOLANDA QUEIROGA DE ASSIS \\
\hline 228. ZENILDA BRASIL \\
\hline
\end{tabular}

O quadro acima nos permite uma primeira constatação: na Paraíba, existe um número expressivo de mulheres que conseguiram, muitas delas, por detrás dos panos, fazer da literatura um exercício feminino e que "passaram a buscar o equilíbrio entre a agulha e a caneta, transgredindo, ora com sutileza, ora com revolta, os padrões culturais que as submetiam. Graças à produção que legaram a todos nós, firmaram uma tradição que merece ser resgatada” (VASCONCELOS, 2003, p. 55). Dito de outra forma, quando pensamos em quem foram as mulheres acima, percebemos que elas foram, em sua maioria, mulheres públicas (professoras, poetisas, romancistas, ativistas culturais, políticas) que se valeram da escrita como ferramenta para atuar em um espaço - o público - marcado por uma dissimetria que aloca homens e mulheres em lugares opostos, completamente antípodas (PERROT, 2005) e que permitia às mulheres circularem para além do espaço privado do lar apenas se isso estivesse ligado às suas funções mundanas e domésticas. Para muitas dessas mulheres, escrever era a condição de própria existência, como pode nos atestar o poema abaixo de Violeta Formiga, poetisa paraibana assassinada, aos 31 anos, pelo próprio companheiro:

\section{VIVÊNCIA}

Faço poema

Como quem faz pão:

Faminta e necessária. 
A leitura do poema acima evidencia que para o eu lírico a literatura é uma necessidade tão vital como o é o ato de comer. Nesse caso, escrever é um ato paradoxal, pois surge de uma fome, mas é, ao mesmo tempo, alimento para essa fome que impulsiona o ato da escrita. Em Violeta Formiga, a literatura é fome, sobretudo, de liberdade, como podemos inferir a partir da leitura de outro poema dela:

\author{
ARENA \\ Entregar-me \\ sem limitações \\ do verbo \\ ou da cena. \\ Você existe \\ na plenitude \\ totalizante \\ do poema.
}

A liberdade por que anseia o eu lírico de Violeta Formiga dar-se-á em sua plenitude por meio do ofício de ser poeta. Nesse caso, o poema é, portanto, alimento, mas fruto da fome de dizer-se em palavras.

Voltando aos nomes elencados no quadro anterior, notamos que aquelas mulheres não corresponderam aos estereótipos de submissão social que se esperam das mulheres. Talvez porque muitas delas fossem professoras e essa profissão viabilizou que rompessem com o que se esperava delas no espaço público, porque lutaram em prol de direitos que não lhes eram outorgados, foram em busca de serem reconhecidas como cidadãs ou denunciaram os desmandos a que eram submetidas ou a violência que era cometida contra elas mesmas ou contra os mais humildes e necessitados. A título de exemplificação, podemos citar Francisca de Oliveira, mais conhecida como Chica da Rocinha, que, em Uma esperança na luta (1986), à maneira de Carolina Maria de Jesus, faz do cotidiano de privação o motivo de sua obra que se preocupa em denunciar as desigualdades sociais:

O que desejo é passar para as pessoas minhas experiências de vida e o que tudo isso significa para mim. Nascer em uma pequena cidade do interior do nordeste, morar no Rio de Janeiro e ter a oportunidade de conhecer a Itália, a França e o Peru. É, também, uma forma de falar das dificuldades que já enfrentei, morando no sertão ou em uma das maiores favelas da zona sul [do Rio de Janeiro] (OLIVEIRA, 1986, p. 10).

Quando lemos a história de vida não só de Chica da Rocinha, mas de muitas das mulheres a que fazemos referência ao longo deste trabalho, as reivindicações e as denúncias que elas fizeram deram-se por meio da participação direta delas no espaço público, mediante mobilizações, protestos, ou 
por meio de escritos que, gestados na intimidade do lar, ganharam o espaço público, descortinando aspectos do mundo privado que revelavam ser este não tão idílico quando se pensava ou se quisera que ele fosse. Dentre essas escritoras transgressoras, podemos citar Maria Ignez da Silva Mariz, que escandalizou a cidade de Sousa ao divorciar-se e que, mediante a colaboração em jornais, lutou em prol da emancipação feminina a partir do direito à educação, com destaque para a educação sexual, e ao trabalho. Para Evandro Nóbrega, Ignez Mariz era uma mulher “independente, socializante, feminista, sem muitas papas na língua” (NÓBREGA, 1994, s/p).

Embora muitas das escritoras a cujos nomes chegamos tenham nascido entre as últimas décadas do século XIX e as primeiras décadas do século XX, é apenas a partir de 1920, como atesta pesquisa de Campos Júnior (2015), que vamos ter a publicação de obras de autoria feminina na Paraíba, produção essa que vai paulatinamente ganhando relevância à medida que novas autoras vão surgindo seja por meio de publicações individuais, seja por meio da participação em coletâneas. Ainda de acordo com a pesquisa de Campos Júnior (2015), o boom dessa produção foi a década de 1990, quando o circuito literário paraibano assiste à publicação de um número expressivo de obras de autoria feminina graças às iniciativas do Núcleo Cultural Português e da Editora Caravela, que fizeram circular as coletâneas “Autores Campinenses” e “Autores Parahybanos”.

Voltando, mais uma vez, ao quadro que apresentamos em páginas anteriores, dentre os nomes de escritoras que ele apresenta, estão, portanto, os de poetisas, cordelistas, romancistas, cronistas, dramaturgas, ensaístas, o que revela que as mulheres paraibanas que se valeram da escrita como ofício não foram ou são escritoras de um gênero só. Mesmo assim, dentre os gêneros literários produzidos pelas escritoras paraibanas predomina a poesia de cunho romântico (CAMPOS JÚNIOR, 2015). A predileção por tal gênero, tendo em vista que estamos falando de escritoras que começaram a publicar nas primeiras décadas do século XX, deve-se, talvez, ao fato de, em sendo a sociedade paraibana análoga à sociedade brasileira, um espaço que confinava as mulheres à esfera privada do lar, a poesia despontar para muitas dessas mulheres como o lugar da fala possível:

Pois escrever poemas era, na maioria dos casos, a única ocasião possível de dizer a si própria, de se construir sujeito de uma fala. É o espaço onde cada uma se oculta ou se desvela, onde uma voz antes silenciosa e silenciada pode dizer $\mathrm{Eu}$, minha, meu, falando da impressão que lhe causa uma paisagem, uma flor, o homem amado. É o espaço onde um Eu se vê escrevendo, consciente de que sua voz ultrapassará os muros espessos do lar, alcançará outras pessoas. Uma fala subversiva.

[...] Esta palavra feminina é uma afirmação, a recusa da solidão, a instituição de um diálogo com o interlocutor possível. Ela diz um ser feminino em seu desejo de ver claro em si, de se relacionar com o próximo. A 
poesia é ao mesmo tempo espaço de evasão, de fuga a um real esmagador e lugar onde outro real é criado, e um Eu se estrutura: no desvelar os atributos ao seu ser, no descrever um fazer feminino, na entrega do pensamento do sujeito lírico diante do Outro, seja ele o amado, uma amiga, o Pai, a Mãe, Deus, o Leitor (FERREIRA, 1991, p. 13-14).

Os nomes das mulheres-escritoras que elencamos no quadro apresentado são, portanto, resíduos de uma presença feminina que teve de lutar contra as coerções de uma sociedade de base falocêntrica para a qual a mulher era incapaz de contribuir porque era "simplesmente" mulher. O resgate dessas escritoras e de suas obras constitui-se, portanto, em uma luta política que visa, por um lado, à desconstrução dos cânones literários que eram (e são) vistos como instâncias balizadoras das obras que deveriam ou não fazer parte de um seleto grupo, o dos canonizados. Por outro lado, o caráter político dessa grande empreitada torna-se mais acentuado, quando, por meio desse empreendimento, se busca, justamente, a (re)construção, em nossa literatura, de uma memória literária feminina cujos caminhos, como argutamente reitera Perrot (2005), “entre fugacidade de traços e oceano de esquecimento”, são bastante estreitos.

Por isso, levando-se em conta a importância que o ato de nomear possui, sobretudo o ato de nomear-se, uma vez que, por exemplo, “o poder de nomear significava para os antigos hebreus dar às coisas a sua verdadeira natureza, ou reconhecê-la” (BOSI, 2000, p. 163), o que os nomes de escritoras que descobrimos mostram é que, mesmo diante da miríade de ações que as impeliam ao esquecimento, as mulheres fizeram da escrita, em suas mais variadas formas, um espaço não só de reivindicação política por melhores condições de trabalho, de denúncia da opressão e da violência do masculino contra o feminino, mas também se valeram da escrita como exercício de descobertas de novas formas de ser/existir e, sobretudo, tiveram na escrita um lugar de memória. Memória de uma presença feminina que muitos quiseram apagar a fim de negar a importância da mulher na construção de uma nova moral, de uma nova cultura, de uma sociedade destituída da discriminação de gênero, do reconhecimento da igualdade de direitos e de acesso em meio à diversidade cultural, razão por que nomear as nossas escritoras é reconhecê-las, dar-lhes visibilidade de forma que possam circular novamente ou, em alguns casos, pela primeira vez.

Para os que trabalham com textos produzidos por sujeitos que estão à margem das estruturas hegemônicas de poder, a descoberta de nomes é um trabalho que adquire matizes diversos que vão além do elencar por elencar porque os textos (re)descobertos nos servem como fonte que, por sua vez, nos possibilita “chegar a novas conclusões sobre a tradição literária das mulheres, saber mais sobre como as mulheres desde sempre enfrentaram seus temores, desejos e fantasias e também as estratégias que adotaram para se expressarem publicamente, apesar de seu confinamento ao pessoal e ao 
privado” (WEIGEL apud MUZART, 2006, p. 76). Nesse sentido, se formos olhar a trajetória das mulheres no universo da escrita, espaço até há pouco tempo tido como prerrogativa masculina, perceberemos o quanto muitas mulheres sofreram e tiveram de lutar para adquirir um teto todo seu em uma arquitetura erguida pelos ditames masculinos. Nessa luta, em que as mulheres intentavam migrar da margem para o centro, muitas delas tiveram sua intelectualidade assujeitada ao outro, ao masculino. Como consequência, boa parte de obras de autoria feminina, quando não, indevidamente, apropriada pelo masculino, foi assinada com pseudônimos ou com um simples nome: “anônima”, ambos os casos, o uso do anonimato e de pseudônimos, foram uma estratégia de que se valeram muitas mulheres para evitar qualquer forma de retaliação, daí por que, em nossa opinião, nomear tais mulheres é mais do que preciso. É um ato político por meio do qual se objetiva mostrar como a mulher passou de objeto a sujeito dos discursos de representação em torno do feminino em uma busca incessante por querer-dizer(-se).

Em outras palavras, se as mulheres tiveram de ficar no anonimato ou precisaram se esconder sob um pseudônimo, o trabalho de identificar os nomes delas e das obras que produziram, tal qual estamos fazendo, não pode ser visto como menor, mas como um dos primeiros e significativos passos dentro de uma perspectiva arqueológica a fim de contribuir para a escritura de uma memória feminina dentro do nosso Estado, sobretudo porque, apesar dos esforços pioneiros de João Lélis, com Maiores e menores (1953), e de Gemy Cândido, com História Crítica da Literatura Paraibana (1983), existe a carência de uma obra que nos dê uma visão do conjunto da produção literária paraibana e que separe a série social da série literária. Com exceção dos trabalhos do crítico Hildeberto Barbosa Filho, estamos pensando especificamente em Arrecifes e lajedos, as obras historiográficas existentes apresentam uma visão culturalista do fenômeno literário e colocam, lado a lado, obras literárias com obras filosóficas, filológicas, historiográficas, geográficas, pedagógicas, políticas, econômicas etc. (BARBOSA FILHO, 2011, p. 13). Essa ausência historiográfica torna, mais ainda, necessários estudos cujo escopo esteja voltado para a produção local, seja ela de autoria masculina, seja de autoria feminina.

No caso da produção literária escrita por mulheres, registremos que, na falta de uma história concisa da literatura local, ainda que a existência de obra semelhante não possa garantir visibilidade para a produção literária de autoria feminina, já que existem muitas mulheres dentre as que identificamos que parecem ser verdadeiras ilustres desconhecidas, a menção a nomes de escritoras paraibanas dá-se através de trabalhos bem pontuais, como os de determinados pesquisadores vinculados às universidades de nosso Estado ou que, sendo de outras instituições, têm interesse por manifestações literárias locais, e como os de críticos já conhecidos em nosso meio intelectual, como o pioneiro Gemy Cândido, os já citados Hildeberto Barbosa Filho e José Mário da Silva, ainda que o espaço dedicado à produção feminina seja o 
rodapé do texto ou a menção rápida, como é o caso da obra História Crítica da Literatura Paraibana, de Gemy Cândido.

Nessa obra, que remete ao século XIX, período em que passam a existir as primeiras manifestações literárias em nosso estado, já que durante todo o período colonial o que tivemos foram obras de cunho informativo que não chegam a ser propriamente literárias, a presença feminina se faz notar mediante a menção apenas aos nomes das escritoras e de suas respectivas obras. Entretanto, o tratamento dado a elas é diferente do que é dispensado aos escritores cujas obras são analisadas em parte ou em sua totalidade mesmo que seja, às vezes, mediante o comentário breve. Este sequer existe quando o artista é do sexo feminino, exceção feita apenas em dois momentos: quando o autor tece uma ligeira apreciação sobre o romance de Glorinha Gadelha e a poesia e a prosa de Rosalina Coelho Lisboa, embora, desta última, ele afirme não pertencer à literatura paraibana, o que é bastante discutível. No plano geral de sua obra, às mulheres-escritoras, Gemy Cândido, seguindo, talvez inconscientemente, uma regra quase geral em nossa historiografia, concede uma menção efêmera graças à qual, porém, algumas das escritoras-paraibanas cujos nomes não aparecem nas obras que constituíram o nosso corpus estariam completamente esquecidas. A título de exemplificação, dentre as mulheres-escritoras que Gemy Cândido menciona, que não constam nas obras que tomamos como corpus, mas cujos nomes já incorporamos no quadro anterior estão: Aldina de Almeida, Nísia Leal, Alba Macieira Ferreira Pires, Ilma Santoro, Germana Vidal, Liana Mesquita, Guiomar Chianca, Palmeira Guimarães, Maria Soares Marques, Ione Gomes Barreto.

Outra obra importante na historiografia literária da Paraíba, sobretudo porque, procurando desvencilhar-se da abordagem culturalista que permeia suas antecessoras, arvora-se de "um suporte analítico calcado na textualidade em função da qual se [procura] verificar as componentes técnico-literárias, estilísticas, temáticas ideológicas dos chamados textos poéticos [...]” (BARBOSA FILHO, 2011, p. 14), é o livro, fruto de uma tese de doutorado, Arrecifes e lajedos: breve itinerário da poesia na Paraíba, do professor e crítico literário Hildeberto Barbosa Filho. É, pois, uma obra que vem preencher, em nossa historiografia, aquela ausência a que nos referíamos antes, isto é, a inexistência de uma obra que, detendo-se nas fases de nossa literatura, apresente uma apreciação de suas tendências, estude os nossos principais autores e autoras bem como proporcione ao leitor não só dados de natureza biobibliográfica, mas, sobretudo, uma avaliação crítica. Tal obra preenche, em parte, esse vazio historiográfico porque, como o próprio subtítulo aponta, se detém apenas a um gênero específico, a poesia, de forma que se constitui, a nosso ver, como uma espécie de história concisa da lírica em solo paraibano, até agora a única no gênero. Falta, pois, quem venha completar a empreitada iniciada pelo professor Hildeberto Barbosa Filho e escreva uma obra que se detenha na história da prosa, da dramaturgia e das outras formas literárias em nosso Estado. 
Dividida em cinco capítulos, além da introdução e das considerações finais, Arrecifes e lajedos, ao traçar as linhas de força centrais da poesia na Paraíba, detém-se em algumas poéticas individuais que são, segundo o autor da referida obra, as mais representativas "quer seja do ponto de vista histórico, quer seja do ponto de vista estético” (BARBOSA FILHO, 2011, p. 67). Assim, em uma primeira fase de nossa poesia que vai das origens ao Simbolismo, o crítico elenca os seguintes nomes:

A matéria terá o seguinte esquema: o momento pré-romântico, com destaque para a poesia de Monteiro de Franca; as repercussões do Romantismo, com as vozes poéticas de Rodrigues de Carvalho, Américo Falcão e Osório Paes; as repercussões do Parnasianismo, com Raul Machado, Guimarães Barreto e Mauro Luna; as repercussões do Simbolismo, com Carlos Dias Fernandes, Pereira da Silva e Silvino Olavo, e a modernidade na poesia de Augusto dos Anjos. (BARBOSA FILHO, 2011, p. 68).

Na fase posterior, apesar da influência das estéticas finisseculares, o referido crítico detém-se nas repercussões do Modernismo no cenário artístico-cultural paraibano durante a década de vinte, enfocando a importância de determinados periódicos, como o jornal A união e a revista Era nova, na propagação dos ideais e no compromisso com as atividades literárias em nosso estado nas duas primeiras décadas do século $X X$, ainda que "as posições estéticas [...], no palco dos debates sobre as novas ideias irradiadas em torno da Semana de Arte Moderna, realizada em São Paulo, em fevereiro de 1922, [sejam] visivelmente tradicionais” (BARBOSA FILHO, 2011, p. 179). Desse período em que os ares de renovação artística quase eram arrefecidos pelo peso do tradicionalismo que grassava em nosso cenário artístico e literário, Hildeberto Barbosa Filho elege como representantes dessa época marcada pela "indecisão face a um credo estético rigorosamente definida" e, portanto, pelo peso passadista e pelo apelo modernista, os nomes de Perylo de Oliveira e Eudes Barros.

Na última fase, voltada para a relação entre poesia e contemporaneidade, no lugar de nomes isolados, o que vai predominar é o surgimento de grupos, como a Geração 59, o Sanhauá e o Caravela, em torno dos quais se aglutinaram poetas, artistas plásticos, músicos e teatrólogos, pondo a nossa produção artístico-literária paraibana em perfeita sintonia com a guerrilha estética promovida, no Brasil, pelos movimentos de vanguarda, como a Poesia Concreta e a Poesia Práxis, e pelo que, antes, fizeram os artistas e intelectuais brasileiros que encabeçaram o movimento modernista, principalmente em sua primeira fase. Passado esse período de rebeldia e ruptura, a poesia na Paraíba, a partir da década de setenta, “aponta para novos rumos, em suas diversas modalidades de dicção individual” (BARBOSA FILHO, 2011, p. 269) nas quais vamos encontrar referências a algumas vozes femininas, embora não na mesma proporção das vozes masculinas. 
Nesse caso, o itinerário da poesia na Paraíba delineado em Arrecifes e lajedos, das origens às tendências contemporâneas, na esteira do que acontece em nossa historiografia oficial, é um percurso que se assenta predominantemente em obras de autoria masculina. Todavia, ao contrário da obra de Gemy Cândido, a de Hildeberto Barbosa Filho apresenta um rol maior de mulheres que compareceram na trajetória lírica na Paraíba: Berna Farias, Violeta Formiga, Maria dos Anjos, América Domiciana, Sheila Maria Costa, Francisca Lopes Pereira, Vitória Lima, Otaciana Cássia, Diracy Vieira, Socorro Leadebal.

Voltando ao que estávamos refletindo acerca dos nomes de mulheres-escritoras que arrolamos neste trabalho, para além do alento de saber que em solo paraibano existe uma tradição de escritoras, ainda a ser (re)descoberta, tais nomes permitem-nos uma última constatação: muitas delas se valeram dos periódicos locais como veículo para a circulação de seus escritos enquanto outras têm, no espaço virtual, um local de divulgação. Sobre esse aspecto, isto é, os dos meios de circulação, acreditamos que, dentre as autoras descobertas, embora muitas tenham editado suas obras, algumas mantêm textos inéditos ou, mesmo que publicados, a tiragem foi tão diminuta que é como se permanecessem inéditos. Se pensarmos que, para se firmar como autor(a), o sujeito que escreve precisa não só publicar, mas fazer com que os seus escritos circulem e obtenham a aceitação do público, não necessariamente da crítica, podemos afirmar, ainda que corramos o risco das generalizações apressadas, que uma parcela significativa das mulheres-escritoras paraibanas não conseguiu sair da condição de escritora e alçar-se à de autora, embora algumas tenham saído do anonimato valendo-se dos períodos e revistas literárias locais como meios de divulgação de seus escritos.

$\mathrm{E}$, aqui, lembremos que os periódicos, não necessariamente os que darão corpo a uma imprensa feminina, foram de extrema importância no processo de publicação, circulação e reconhecimento de mulheres como escritoras. Em âmbito local, as fontes por nós consultadas fazem menção ao suplemento TUDO, do antigo Diário da Borborema, que arregimentou muitas das mulheres-escritoras paraibanas, e o Correio das Artes, suplemento do jornal $A$ união, por cujas páginas os escritos de autoria feminina também circula(ra)m. Aliás, em se tratando de literatura na Paraíba, devemos lembrar que, devido às restrições e dificuldades locais, valer-se de jornais como veículo de circulação da produção literária não foi algo a que apenas as mulheres recorreram:

Na verdade, um dos traços característicos da literatura e, em especial, das manifestações poéticas locais, é sua constante vinculação, desde as origens até os tempos atuais, com as atividades jornalísticas, seja através dos diários, com seus cadernos especiais ou seus suplementos literários, seja através das revistas de cultura. Este vínculo é também permeado pela atuação mais ou menos sistemática das instituições culturais. (BARBOSA FILHO, 2011, p. 55). 
Ainda do consórcio entre literatura e jornalismo, este como meio de escoamento daquela, considerando-se as escritoras arroladas em quadro anterior, parece-nos, mas isso só uma pesquisa mais acurada pode confirmar, que muitas delas não foram além do que publicaram nos suplementos literários, isto é, não conseguiram fazer do trabalho literário um exercício permanente, destino que muitos homens que incursionaram pelas veredas literárias tiveram. Outras dessas escritoras, porém, felizmente, não tiveram a mesma sorte e nos legaram uma obra considerável que ainda está por ser devidamente estudada e avaliada.

Sabemos que nem todas as escritoras resgatadas serão canonizadas porque a natureza própria do cânone é ser excludente e também porque não é objetivo dos estudos de resgate promover a canonização dos/as até então esquecidos/as. No entanto, é preciso que, como críticos, pesquisadores, estudiosos, possamos conhecer os/as “canonizáveis”. Consequentemente, em se tratando da produção de autoria feminina, tendo "o conhecimento das tradições literárias das mulheres, o percurso, as dificuldades e mesmo as estratégias utilizadas para romper o confinamento cultural em que se encontravam” (DUARTE, 1990, p. 76), esperamos poder ter, a partir de um esforço analítico e interpretativo de cunho feminista, condições de construirmos um mosaico que mostre que as mulheres na Paraíba, em consonância com outras mulheres-escritoras do país afora, escreveram bem mais do que sobre o amor e as flores.

\section{Referências}

ALMEIDA, HERIBERTO COELHO DE (org.). Antologia Contemporânea da Poesia Paraibana. Paraíba: O Sebo Cultural, 1995.

BARBOSA FILHO, Hildeberto. Arrecifes e lajedos: breve itinerário da poesia na Paraíba. João Pessoa: Editora da Universidade Federal da Paraíba, 2011.

Vocábulos e veredas: tópicos de Literatura Paraibana. João Pessoa: Manufatura, 2003.

BOSI, Alfredo. Poesia-resistência. In: . O ser e o tempo da poesia. São Paulo: Companhia das Letras, 2000. p. 163-227.

CÂNDIDO, Gemy. História crítica da literatura paraibana. Governo do Estado da Paraíba, Secretaria de Educação e Cultura/Diretoria Geral de Cultura. João Pessoa: A União, 1983.

CAMPOS, Maria Consuelo Cunha. Gênero. In: JOBIM, José Luís (org.). Palavras da crítica: tendências e conceitos no estudo da literatura. Rio de Janeiro: Imago, 1992. (Biblioteca Pierre Menard). p. 111-125. 
CAMPOS JÚNIOR, José de Sousa. “À sombra da gameleira”: literatura contemporânea e os rumos da produção feminina na Paraíba. 2015. 239f. (Dissertação em Literatura e Interculturalidade). Universidade Estadual da Paraíba. Campina Grande. 2015.

CASTRO, Ângela Bezerra de et.al. (org.). Coletânea Autores Paraibanos - Poesia. João Pessoa: GRAFSET, 2005.

2005.

. Coletânea Autores Paraibanos - Prosa. João Pessoa: GRAFSET,

COELHO, Nelly Novaes. Dicionário crítico de escritoras brasileiras (1711 - 2001). São Paulo: Escrituras Editora, 2002.

DUARTE, Constância Lima. Mulheres em Letras: antologia de escritoras mineiras. Florianópolis: Editora Mulheres, 2008.

Literatura feminina e crítica literária. In: GAZOLLA, Ana Lúcia Almeida. A mulher na literatura. vol I. Belo Horizonte: Imprensa da Universidade Federal de Minas Gerais, 1990. p. 70-79.

FERREIRA, Luzilá Gonçalves. Em busca de Thargélia: poesia escrita por mulheres em Pernambuco no segundo Oitocentismo (1870-1920). Tomo I. Recife: FUNDARPE, 1991.

FORMIGA, Violeta. Contra cena. João Pessoa: Edições Macunaíma, 1983.

FLORES, Hilda Agnes Hübner. Dicionário de Mulheres. Porto Alegre: Nova Dimensão, 1999.

HOLLANDA, Heloisa Buarque de; ARAÚJO, Lúcia Nascimento. Ensaístas Brasileiras. Rio de Janeiro: Rocco, 1993.

KOTHE, Flavio René. (1997). O cânone colonial. Brasília: UNB.

LÉLIS, João. Maiores e menores. João Pessoa: Editora Teone LTDA., 1953.

MARINHEIRO, Elizabeth. Dicionário Biobibliográfico do Autor da Microrregião do Agreste da Borborema. Campina Grande: CNPQ, Universidade Federal da Paraíba, Universidade Regional do Nordeste, 1982.

MENDES, Algemira de Macêdo; ALBUQUERQUE, Marleide Lins de; ROCHA, Olívia Candeia Lima (orgs.). Antologia de escritoras piauienses: século XIX à contemporaneidade. Teresina: FUNDAC/FUNDAPI, 2009.

MUZART, Zahidé Lupinacci. Poeira de arquivo: vozes da belle-époque. In: CAVALCANTI, Ildney; LIMA, Ana Cecília Acioli e SCHNEIDER, Liane (orgs.). Da mulher às mulheres: dialogando sobre literatura, gênero e identidades. Maceió: EDUFAL, 2006. p.76-82. 
. (org.). Escritoras Brasileiras do Século XIX: antologia. v. 1. Florianópolis: Editora Mulheres, 2000.

. (org.). Escritoras Brasileiras do Século XIX: antologia. 2. ed. rev. v. 2. Florianópolis; Santa Cruz do Sul: Editoras Mulheres; EDUNISC, 2004.

(org.). Escritoras Brasileiras do Século XIX: antologia. 2. ed. rev. v. 3. Florianópolis: Editora Mulheres; CNPQ, 2009.

NÓBREGA, Evandro. Prefácio da 2. ed. In.: MARIZ, Ignez. A barragem. João Pessoa: A união, 1994. Não paginado.

OLIVEIRA, Francisca de (Chica da Rocinha). Uma esperança na luta. Rio de Janeiro: Cooperativa Brasileira do Autor Sindicalizado, 1986.

PERROT, Michelle. As mulheres ou os silêncios da história. Trad. Viviane Ribeiro. São Paulo: EDUSC, 2005.

SCHMIDT, Rita. Repensando a cultura, a literatura e o espaço da autoria feminina. In: NAVARRO, Márcia Hoppe (orgs.). Rompendo o silêncio: gênero e literatura na América Latina. Porto Alegre: Editora Universitária/ UFRGS, 1995. .p. 182-189. (Coleção Ensaios CPG - Letras, n. 3)

VASCONCELOS, Eliane. Uma arqueologia da autoria feminina no Brasil. In: SÜSSEKIND, Flora, DIAS, Tânia e AZEVEDO, Carlito (orgs.). Vozes femininas: gênero, mediações e práticas de escrita. Rio de Janeiro: 7letras; Casa Rui Barbosa, 2003. p. 54-60.

SANTOS, Idelette Muzart Fonseca dos. Dicionário Literário da Paraíba. João Pessoa: A UNIÃO, 1994.

RUFFATO, Luiz (org.). 25 mulheres que estão fazendo a nova Literatura Brasileira. Rio de Janeiro: Record, 2004.

- Mais 30 mulheres que estão fazendo a nova Literatura Brasileira. Rio de Janeiro: Record, 2005.

SCHUMAHER, Schuma; BRAZIL, Érico Vital. Dicionário de mulheres do Brasil de 1500 até a atualidade. Rio de Janeiro: Jorge Zahar Editor, 2000.

Enviado em maio/2018.

Recebido em dezembro/2018. 